\title{
PREPARATION OF GRAPHITE TARGETS IN THE GLIWICE RADIOCARBON LABORATORY FOR AMS ${ }^{14} \mathrm{C}$ DATING
}

\author{
Justyna Czernik • Tomasz Goslar \\ Institute of Physics, Silesian University of Technology, ul. Krzywoustego 2, 44-100 Gliwice, Poland. \\ Email: justyna@fizyk.matfiz.polsl.gliwice.pl.
}

\begin{abstract}
A line for preparation of graphite targets for accelerator mass spectrometry (AMS) radiocarbon dating has been built in the Gliwice ${ }^{14} \mathrm{C}$ Laboratory. The AMS ${ }^{14} \mathrm{C}$ measurements of our targets are performed in the Leibniz-Labor für Altersbestimmung, Kiel, Germany. The quality of our line has been tested in two series of AMS ${ }^{14} \mathrm{C}$ measurements of background and Ox-II standard samples and by measurements of the amount of $\mathrm{CO}_{2}$ released during combustion of sample-free quartz tubes. Most background contamination in the first series was introduced during combustion, which has been greatly reduced by baking quartz tubes vacuum-sealed with $\mathrm{CuO}$ and $\mathrm{Ag}$. The residual contamination (ca. $1.5 \mu \mathrm{g} \mathrm{C}$ ) seems to come mostly from the quartz tubes themselves. At present, most of the contamination of the background is introduced during graphitization. The reproducibility of background preparations is satisfactory, especially for samples larger than $1.5 \mathrm{mg}$, when it is better than $\pm 0.09 \mathrm{pMC}$. Despite still significant contamination with low- ${ }^{14} \mathrm{C}$ carbon during the graphitization process (corresponding to $1.2 \pm 0.2 \%$ of ${ }^{14} \mathrm{C}$-free carbon), the good reproducibility of the results allows us to use our line in routine ${ }^{14} \mathrm{C}$ dating.
\end{abstract}

\section{INTRODUCTION}

In the accelerator mass spectrometry (AMS) technique of radiocarbon dating, the ${ }^{14} \mathrm{C}$ concentration is measured in graphite, which is prepared from the carbon contained in the sample. Graphite is pressed into a tablet, which is used as a target in the Cs-sputtering ion source of the accelerator. There are several AMS ${ }^{14} \mathrm{C}$ laboratories in Europe, where graphite targets are produced and measured. In some other laboratories (e.g. Sveinbjörnsdottir et al. 1993; Thomsen and Gulliksen 1992), graphite targets are produced and measured in collaboration with the AMS labs. In the ${ }^{14} \mathrm{C}$ laboratory in Gliwice, Poland, a system to produce graphite targets for AMS ${ }^{14} \mathrm{C}$ measurements have also been built. This system is dedicated to routine ${ }^{14} \mathrm{C}$ dating of small organic samples, in cooperation with the Leibniz-Labor für Altersbestimmung und Isotopenforschung, Kiel, Germany (Nadeau et al. 1997, 1998). The whole system consists of equipment for chemical preparation, sample combustion and $\mathrm{CO}_{2}$ purification, and for production of carbon powder and accelerator targets.

Because the sample mass needed to prepare graphite for AMS targets is small (ca. $1 \mathrm{mg}$ of carbon), there is a problem of purity during the whole process of preparing the graphite target. This paper presents the tests of quality of our system, performed by ${ }^{14} \mathrm{C}$ AMS measurements of background and Ox-II standard samples, gives evaluation of several sources of contamination, and discusses some experiments to reduce that contamination.

\section{Preparation of Graphite Targets for the AMS ${ }^{14} \mathrm{C}$ Measurement}

The schematic of our lines to produce the graphite targets is shown in Figure 1. All parts of the vacuum lines, which are in contact with the sample, are made of glass, quartz, and stainless steel. The design of the graphitization reactor and the parts for cracking quartz tubes is similar to those used in the Leibniz-Labor (Nadeau et al. 1997, 1998). In the first stage, the vacuum lines worked with an oil diffusion pump.

Organic samples are pretreated with the AAA method (acid-alkali-acid). After pretreatment, the wet sample is transferred to the quartz tube (pre-baked in $900{ }^{\circ} \mathrm{C}$ for $5 \mathrm{hr}$ ) and dried. The quartz tube with sample, $\mathrm{CuO}$ and $\mathrm{Ag}$ is evacuated to a pressure of $10^{-4} \mathrm{mbar}$ and sealed. The sample is combusted at a temperature $900{ }^{\circ} \mathrm{C}$ for $5 \mathrm{hr}$. After combustion, the quartz tube with the gaseous sample is connected to the vacuum line, evacuated to $10^{-4} \mathrm{mbar}$, cracked under vacuum, and the $\mathrm{CO}_{2}$

(C) 2001 by the Arizona Board of Regents on behalf of the University of Arizona Radiocarbon, Vol 43, Nr 2A, 2001, p 283-291

Proceedings of the 17 th International ${ }^{14} \mathrm{C}$ Conference, edited by I Carmi and $\mathrm{E}$ Boaretto 


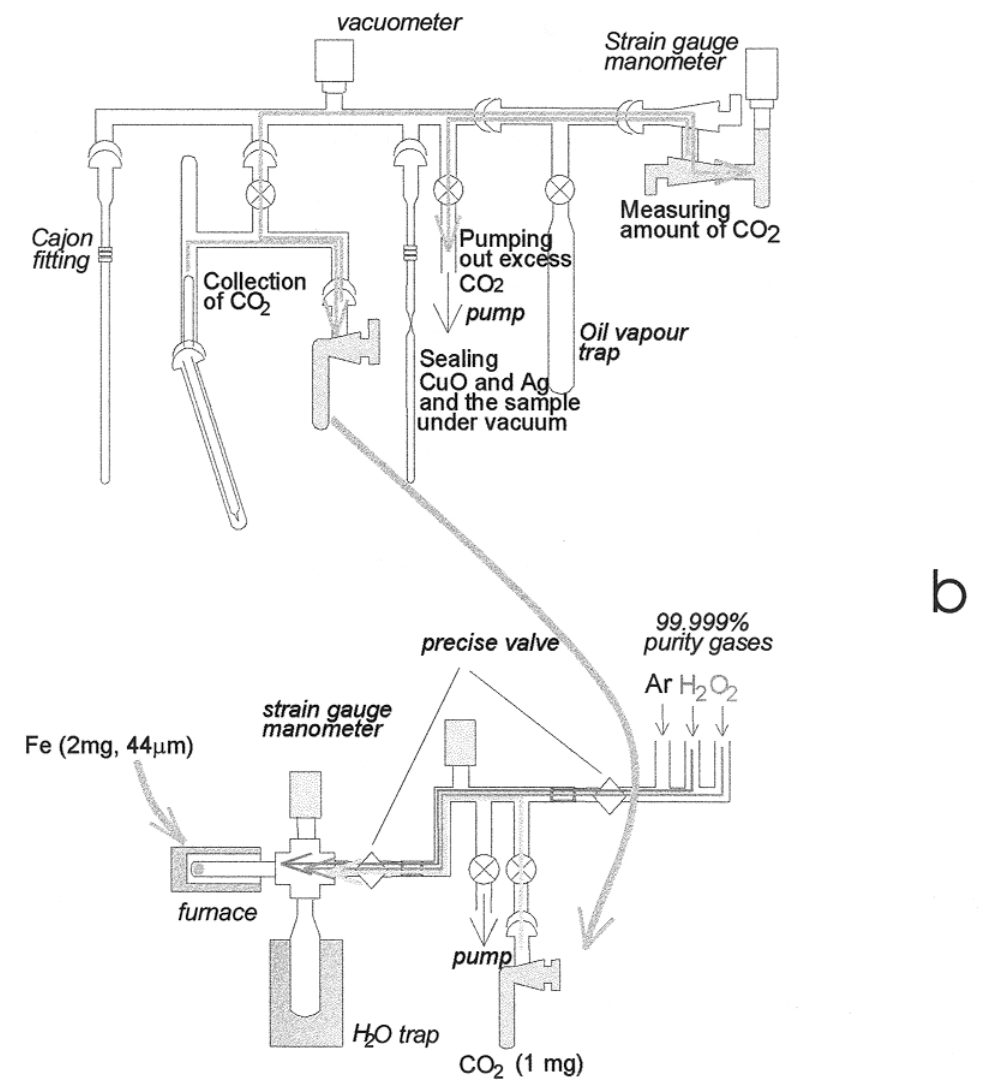

Figure 1 Lines and procedures of preparation of graphite targets in the Gliwice Radiocarbon Laboratory for AMS ${ }^{14} \mathrm{C}$ dating

obtained during combustion is collected in a glass vessel in liquid nitrogen (Figure 1a). Prior to collection of $\mathrm{CO}_{2}$, gaseous impurities (mostly water vapor) are trapped in a mixture of dry ice and alcohol for $10 \mathrm{~min}$. An amount of $\mathrm{CO}_{2}$ corresponding to $1 \mathrm{mg}$ of carbon (controlled by measuring pressure in a known volume) is then separated and transferred to the reduction line (Figure 1b). Graphite is obtained by the reduction of $\mathrm{CO}_{2}$ in hydrogen over an iron catalyst at $600{ }^{\circ} \mathrm{C}$, and it is deposited on the iron powder. Before the reduction of $\mathrm{CO}_{2}$, the iron powder is oxidized $(15 \mathrm{~min})$, and then reduced in hydrogen $(30 \mathrm{~min})$, both processes kept at $400{ }^{\circ} \mathrm{C}$. After the graphitization is completed, the mixture of carbon and iron is pressed into a target holder and stored in argon until measurement. Details of our system and procedures are described by Goslar and Czernik (2000).

\section{QUALITY TEST OF OUR SYSTEM}

To test the quality of our system, we prepared several samples of ${ }^{14} \mathrm{C}$ background (coal) and standard $(\mathrm{Ox}-\mathrm{II})$. These tests were performed in two series. In the first series, we followed the procedures described by Goslar and Czernik (2000). Then we made several experiments to improve our system, and checked our achievement in the second series of ${ }^{14} \mathrm{C}$ measurements. 


\section{First Series of ${ }^{14} \mathrm{C}$ Measurements}

This series shows (Figure 2a) an increase of background with decreasing sample mass, related to a constant amount of impurity introduced during preparation (e.g. Vogel et al. 1987). Extremely high contamination ( $>1 \mathrm{pMC}$ for combustion mass $>1 \mathrm{mg} \mathrm{C}$ ) occurred when the quartz tubes with Ox-II and coal were pumped out simultaneously at the same vacuum line (Figure 1a). We observed then a piece of the Ox-II raised/blown from the tube into the vacuum line. It can not be excluded that some parts of it did also fall into the tubes with coal. Another source of contamination might be the quartz tubes themselves, when they were not pumped sufficiently out (cf. section below). The Ox-II samples were obviously contaminated with "older" carbon, this contamination being quite variable (corresponding to $1.5-3 \%$ of ${ }^{14} \mathrm{C}$-free carbon; Figure $2 b$ ).

\section{Experiments with Lowering Contamination During the Combustion Process}

The contamination level is a sum of mass-independent and mass-dependent fractions. The mass dependent fraction is due to contamination introduced in the pretreatment and combustion steps. It is generally accepted that the contamination may come from the walls of the tubes (Vogel et al. 1987) or CuO (Vandeputte et al. 1998) used for combustion, or from degassing grease and other components of the vacuum systems. It has also been shown that most impurities from tubes and $\mathrm{CuO}$ can be eliminated by baking at high temperature (Vandeputte et al. 1998; Kirner et al. 1995; McNichol et al. 1995; Pearson et al. 1998). To reduce the contamination in our system, we have made several trials with combustion of sample-free quartz tubes and we checked our progress by measuring the amount of $\mathrm{CO}_{2}$ released from cracked tubes, using a calibrated vacuometer (with accuracy of ca. 10\%). These experiments (numbered from 1 to 9 ) are listed in Table 2 and described in detail below. The results of particular experiments are shown in Figure 3.

It appeared that sealing the evacuated tubes under good vacuum is critical for the contamination level. Some tubes sealed under small leakage (Table 2, Figure 3; experiment 1) gave a large contamination of samples. This effect may explain the outlying results in the first series of background tests.

In our experiments we used quartz tubes combusted with $\mathrm{CuO}$ baked in oxygen (the standard method, used in the first series of AMS ${ }^{14} \mathrm{C}$ tests), and also with fresh $\mathrm{CuO}$, and with $\mathrm{CuO}$ baked in air in a muffle oven (experiments 2-4). Surprisingly, the amount of $\mathrm{CO}_{2}$ obtained in these procedures appeared not dependent on the $\mathrm{CuO}$ preparation method and it corresponds to about $5.8 \mu \mathrm{g}$ of carbon.

Significant reduction of contamination was observed when the quartz tubes sealed with $\mathrm{CuO}$ and $\mathrm{Ag}$ under vacuum were baked in $900{ }^{\circ} \mathrm{C}$, opened in an atmosphere of oxygen, filled with the sample and only then sealed under vacuum for combustion (experiments 5 and 6). This lowered the contamination to $1.80 \pm 0.30 \mu \mathrm{g}$. In this part of our experiments we also used different amounts of $\mathrm{CuO}$, showing that the contamination was not dependent on $\mathrm{CuO}$ mass (Figure 3).

At some stage we got a new batch of quartz tubes (experiments 7-9), which appeared much cleaner than the former ones (cf. experiments 2-4 and 7-9 in Figure 3). Contamination of vacuum-baked quartz tubes from the new batch corresponds to $1.4 \pm 0.2 \mu \mathrm{g}$ of carbon.

\section{Second Series of ${ }^{14} \mathrm{C}$ Measurements}

All the combustions for the second series of ${ }^{14} \mathrm{C}$ tests were made in the vacuum-baked quartz tubes from the second batch. We proceeded with our coal and Ox-II, as well as with portions of coal and 


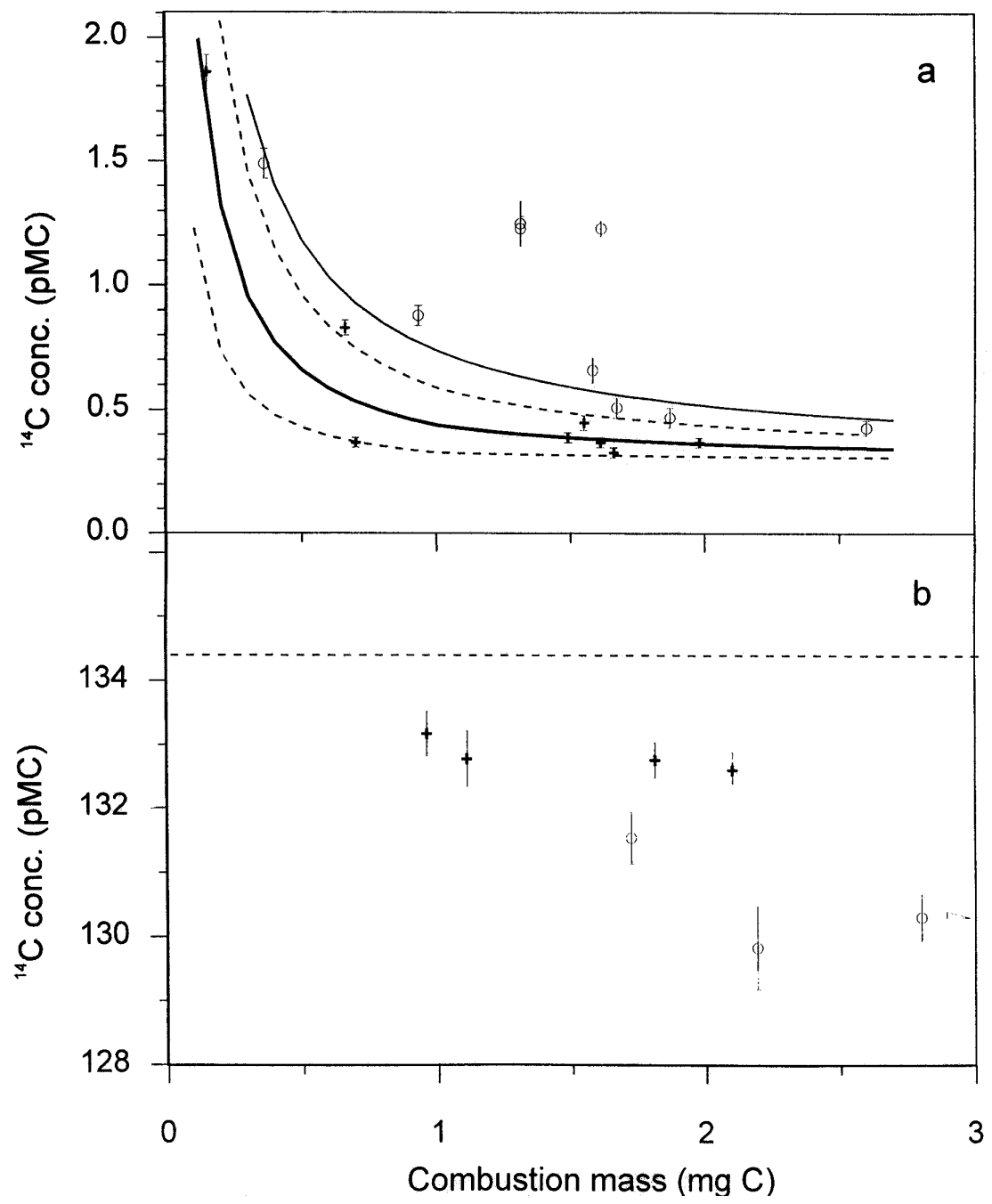

Figure 2 Results of ${ }^{14} \mathrm{C}$ AMS measurements of background (a) and standard (b) samples prepared in the Gliwice ${ }^{14} \mathrm{C}$ Laboratory. o - first series; + - second series of preparation. The error bars represent solely the precision of AMS measurement. The sample marked with horizontal arrow was prepared from $\mathrm{CO}_{2}$ supplied from conventional ${ }^{14} \mathrm{C}$ laboratory (sample mass about $5 \mathrm{~g} \mathrm{C}$ ). Solid lines in part "a" show functions fitted to first series (thinner line) and second series (thicker line) of results (with parameters given in Table 3). Two dashed lines represent uncertainty of background in the present state of our system. Dashed line in part "b" represents "true" ${ }^{14} \mathrm{C}$ concentration in the Ox-II samples.

Ox-II supplied by the Leibniz-Labor. We also graphitized comparison $\mathrm{CO}_{2}$ samples from IAEA C1 (Carrara marble) and Ox-II materials prepared at the Leibniz-Labor.

Before preparation of the second series of samples, we replaced the diffusion pump with turbomolecular pump and introduced a liquid nitrogen trap to freeze vapours close to the main body of the line. Since then, we obtain a much better vacuum. Also we avoided pumping out the line with the rotary pump. 


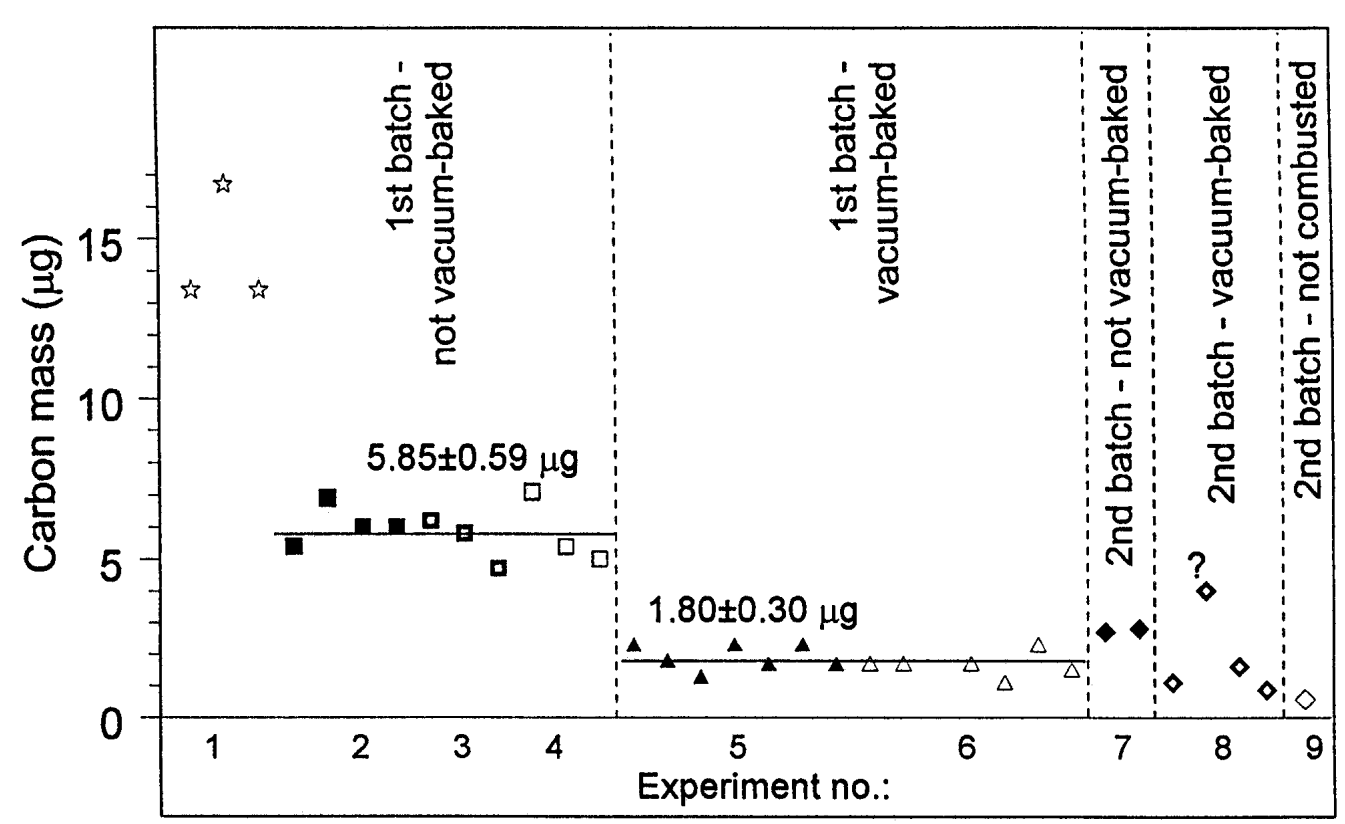

Figure 3 Amount of carbon released after combustion of sample-free quartz tubes. The numbers 1 to 9 correspond to experiments listed in Table 2 and described in the text. Different symbols were used to distinguish the results of different experiments. The mean masses of carbon released from not vacuum-baked and vacuumbaked tubes of the first batch are given.

${ }^{14} \mathrm{C}$ measurements of the first series of Ox-II samples indicated serious and variable contamination with carbon of lower ${ }^{14} \mathrm{C}$ activity. Significant reduction of that contamination has been obtained in the second series (Table 1 and Figure 2b). The agreement of the results obtained for targets from Gliwice and Kiel Ox-II batches, and for samples combusted in the two laboratories strongly suggest that the contamination is introduced during graphitization and/or cracking of the quartz tubes. The latter possibility, however, seems less probable, since the contamination is independent of combustion mass. Moreover, cracking of the uncombusted quartz tube released less than $1 \mu \mathrm{g} \mathrm{C}$ (experiment 9). The contamination seems rather constant (corresponding to $1.2 \pm 0.2 \%$ of ${ }^{14} \mathrm{C}$-free carbon), which is quite acceptable in routine ${ }^{14} \mathrm{C}$ dating. Significant improvement in the second series has also been obtained for background samples (Table 1 and Figure 2a).

\section{Evaluation of Contamination Sources}

Using the mass-dependence of the ${ }^{14} \mathrm{C}$ concentration in background samples we tried to recognize the sources of contamination in our system. One would expect that contamination with a constant amount of modern carbon during combustion would lead to ${ }^{14} \mathrm{C}$ concentrations inversely proportional to the combustion mass. Similarly, a constant amount of contamination introduced during graphitization would effect a similar dependence of ${ }^{14} \mathrm{C}$ concentration on graphitization mass. The third component $\left(A_{o}\right)$ may give a constant contribution to ${ }^{14} \mathrm{C}$ concentration. It appears when the amount of contamination is proportional to the graphitization mass (e.g. when C-containing vapours are released from the reactor elements proportionally to $\mathrm{CO}_{2}$ and $\mathrm{H}_{2}$ pressure). Hence, ${ }^{14} \mathrm{C}$ concentration in the background sample $\left(A_{b}\right)$ may be expressed with the equation:

$$
A_{b}=c_{c} \times A_{c} / m_{c}+c_{g} \times A_{g} / m_{g}+A_{o}=k_{c} / m_{c}+k_{g} / m_{g}+A_{o}
$$


Table 1 Results of AMS ${ }^{14} \mathrm{C}$ measurements of background and standard samples prepared in the Gliwice ${ }^{14} \mathrm{C}$ Laboratory

\begin{tabular}{lcccrr}
\hline Sample & AMS & $\begin{array}{c}\text { Combustion } \\
\text { mass } \\
(\mathrm{mg} \mathrm{C})\end{array}$ & $\begin{array}{c}\text { Graphitization } \\
\text { mass } \\
(\mathrm{mg} \mathrm{C})\end{array}$ & \multicolumn{1}{c}{${ }^{14} \mathrm{C}$} \\
\hline First series & Lab nr & Lab nr & \\
CO $_{2}$ Ox-II Gliwice & - & KIA & - & 1.01 & $130.31 \pm 0.36$ \\
Coal Gliwice & GdA-5 & 7857 & 2.6 & 0.86 & $0.43 \pm 0.03$ \\
Coal Gliwice & GdA-28 & 9532 & 1.31 & 1.20 & $1.25 \pm 0.09$ \\
Coal Gliwice & GdA-29 & 9533 & 1.31 & 1.17 & $1.23 \pm 0.05$ \\
Ox-II Gliwice & GdA-30 & 9534 & 2.19 & 1.23 & $129.83 \pm 0.65$ \\
Coal Kiel & GdA-32 & 9535 & 1.87 & 1.19 & $0.47 \pm 0.04$ \\
Coal Gliwice & GdA-33 & 9536 & 1.58 & 1.27 & $0.66 \pm 0.05$ \\
Coal Gliwice & GdA-35 & 9537 & 0.36 & 0.36 & $1.49 \pm 0.06$ \\
Coal Gliwice & GdA-37 & 9538 & 0.93 & 0.84 & $0.88 \pm 0.04$ \\
Coal Gliwice & GdA-38 & 9539 & 1.67 & 1.16 & $0.51 \pm 0.04$ \\
Coal Gliwice & GdA-39 & 9540 & 1.61 & 1.13 & $1.23 \pm 0.03$ \\
Ox-II Gliwice & GdA-40 & 9541 & 1.72 & 1.06 & $131.54 \pm 0.04$ \\
Second series & & & & & \\
Ox-II Kiel & GdA-51 & 11055 & 1.11 & 0.91 & $132.78 \pm 0.44$ \\
CO ${ }_{2}$ IAEA C1 & GdA-52 & 11056 & - & 1.09 & $0.33 \pm 0.02$ \\
CO ${ }_{2}$ Ox-II Kiel & GdA-53 & 11054 & - & 0.81 & $133.17 \pm 0.35$ \\
Coal Kiel & GdA-54 & 11329 & 1.98 & 0.99 & $0.37 \pm 0.02$ \\
Coal Gliwice & GdA-56 & 11330 & 1.49 & 1.10 & $0.39 \pm 0.02$ \\
Coal Gliwice & GdA-57 & 11331 & 1.55 & 1.01 & $0.45 \pm 0.03$ \\
Coal Kiel & GdA-58 & 11332 & 0.70 & 0.60 & $0.37 \pm 0.02$ \\
Coal Gliwice & GdA-60 & 11333 & 0.66 & 0.55 & $0.83 \pm 0.03$ \\
Ox-II Gliwice & GdA-61 & 11334 & 2.10 & 1.09 & $132.60 \pm 0.28$ \\
Coal Gliwice & GdA-64 & 11335 & 0.15 & 0.12 & $1.86 \pm 0.07$ \\
Ox-II Gliwice & GdA-65 & 11336 & 1.81 & 1.00 & $132.76 \pm 0.28$ \\
Coal Gliwice & GdA-72 & 11342 & 1.61 & 1.05 & $0.37 \pm 0.02$ \\
\hline & & & & &
\end{tabular}

where $m$ denotes mass of sample (in terms of mass of carbon), $c=$ mass of contamination, and $A=$ ${ }^{14} \mathrm{C}$ concentrations in contamination, and indices ${ }_{\mathrm{c}}$ and $\mathrm{g}$ denote combustion and graphitization, respectively.

The contribution of three background components has been estimated by multiple linear regression of ${ }^{14} \mathrm{C}$ concentration versus inverse of combustion mass and graphitization mass. The results (Table 3 ) indicate significant contribution of mass-independent component $A_{o}$ (i.e. of contamination with amount proportional to sample mass), and suggest a reduction of the combustion contamination in the second series. The component dependent on graphitization mass remains unclear, but probably negligible.

Significant reduction of the $m_{c}$-dependent contamination has been suggested by direct measurements of the $\mathrm{CO}_{2}$ amount released from combusted sample-free quartz tubes (Figure 3). Two potential sources of contamination are carbon impurities in the $\mathrm{CuO}$ and the quartz itself (Vogel et al. 1987; Vandeputte et al. 1998). Comparison of $c_{c}$ and regression parameter $k_{c}$ (Table 3) in the first series $\left(5.85 \mu \mathrm{g}\right.$ and $0.44 \mathrm{mg} \times \mathrm{pMC}$ ) suggests a ${ }^{14} \mathrm{C}$ concentration in the contamination of around 80 
pMC, in agreement with the ${ }^{14} \mathrm{C}$ concentration in commercial $\mathrm{CuO}$ measured by Vandeputte et al. (1998). This would suggest that the main source of radiocarbon in the first series of combustions was copper oxide. This contamination seems entirely removed by vacuum-baking of quartz tubes (experiments 5 and 6, cf. Figure 3, Table 2), after which no dependence between amount of released $\mathrm{CO}_{2}$ and amount of $\mathrm{CuO}$ was observed. This means that the residual contamination $(1.8 \mu \mathrm{g} \mathrm{C}$, cf. Figure 3 ) comes mostly from the quartz itself. The ${ }^{14} \mathrm{C}$ content of this carbon seems similar to modern, but its exact value remains unknown.

Table 2 Parameters of combustion procedures used in the tests of combustion contamination (Figure 3)

\begin{tabular}{|c|c|c|c|}
\hline Experiment & $\begin{array}{l}\text { Quartz } \\
\text { tubes }\end{array}$ & Procedure & Parameters \\
\hline 1 & 1st batch & No vacuum-baking & $\begin{array}{l}500 \mathrm{mg} \mathrm{CuO}(\text { fresh}) ; 150 \mathrm{mg} \mathrm{Ag} \text {; } \\
\text { leakage }\left(5 \times 10^{-4} \mathrm{mbar} / \mathrm{min}\right) \text { during pumping } \\
\text { out; pumping out together with tubes with } \\
\text { oxalic acid }\end{array}$ \\
\hline 2 & & & $500 \mathrm{mg} \mathrm{CuO} \mathrm{(fresh);} 150 \mathrm{mg} \mathrm{Ag}$ \\
\hline 3 & & & $\begin{array}{l}500 \mathrm{mg} \mathrm{CuO} \text { (pre-baked in oxygen); } 150 \mathrm{mg} \\
\mathrm{Ag}\end{array}$ \\
\hline 4 & & & $500 \mathrm{mg} \mathrm{CuO}$ (pre-baked in air); $150 \mathrm{mg} \mathrm{Ag}$ \\
\hline 5 & & Vacuum-baking & $500 \mathrm{mg} \mathrm{CuO}$ (fresh); $150 \mathrm{mg} \mathrm{Ag}$ \\
\hline 6 & & & $150 \mathrm{mg} \mathrm{CuO}$ (fresh); $70 \mathrm{mg} \mathrm{Ag}$ \\
\hline 7 & 2nd batch & No vacuum-baking & $150 \mathrm{mg} \mathrm{CuO}$ (fresh); $70 \mathrm{mg} \mathrm{Ag}$ \\
\hline 8 & & Vacuum-baking & 150 mg CuO (fresh); 70 mg Ag \\
\hline 9 & & No combustion & $150 \mathrm{mg} \mathrm{CuO}$ (fresh); $70 \mathrm{mg} \mathrm{Ag}$ \\
\hline
\end{tabular}

Judging from experiment 8 (Figure 3) one would expect still lower combustion contamination in the second series of AMS measurements, where the new batch of quartz tubes was used. The mean amount of released carbon $(1.4 \mu \mathrm{g})$ seems concordant with the best estimate for $k_{c}(0.15 \mathrm{mg} \times \mathrm{pMC})$, but the error of the latter estimate is large, and it cannot be used as a confirmation of the $\mathrm{CO}_{2}$-release tests.

The constant component $A_{o}$ seems similar, or even the same, in both series, and it appears to be the main component of background for samples larger than $1 \mathrm{mg} \mathrm{C}$. Presumably, it is introduced during graphitization, an effect confirmed by ${ }^{14} \mathrm{C}$ measurements of the IAEA $\mathrm{C} 1$ sample. The $\mathrm{CO}_{2}$ of that sample has been graphitised in our line, giving $0.33 \pm 0.02 \mathrm{pMC}$. This is much higher than the 0.08 \pm 0.03 pMC obtained for samples graphitised from the same $\mathrm{CO}_{2}$ in the Kiel laboratory (Nadeau et al. 2001). As the machine blank in the Kiel accelerator is $0.02 \pm 0.01 \mathrm{pMC}$, the contamination introduced in our line is between 0.25 and $0.3 \mathrm{pMC}$. The lower limit of that range represents the case where the $\mathrm{CO}_{2}$ from $\mathrm{C} 1$ carbonate prepared in $\mathrm{Kiel}$ has $0.1 \mathrm{pMC}$, which is not excluded judging from the studies of Schleicher et al. (1998). At any rate, our constant component $A_{o}$ is distinctly larger than in the Kiel system.

The large reduction of the Ox-II standard contamination in the second series (from ca. $3 \%$ to $1 \%$ ) was not accompanied by a similar reduction of background contamination. This indicates at least two sources of contamination with different ${ }^{14} \mathrm{C}$ concentration. One source in the first series might be oil vapors (of diffusion as well as rotary pumps), which has been eliminated after application of the turbomolecular pump. The other sources, however, remain unknown. 
The precision of ${ }^{14} \mathrm{C}$ dating is limited by the reproducibility of background and standard (Ox-II) contamination, expressed by the scatter of data points in Figures $2 \mathrm{a}$ and $2 \mathrm{~b}$. The high scatter of background points in the first series was determined mostly by three points $>1 \mathrm{pMC}$, either contaminated with Oxalic Acid or not sufficiently pumped out because of leakage. The reality of the above causes seems to be confirmed by the second series, where the leakage and presence of Oxalic Acid were avoided and where such a high contamination of background did not occur. In that series, background reproducibility is still not ideal, as shown by significant ${ }^{14} \mathrm{C}$ difference for two points at about $0.7 \mathrm{mg} \mathrm{C}$. The higher ${ }^{14} \mathrm{C}$ concentration (sample GdA-60) has been obtained from a quartz tube, where patches of rough surface appeared on its outer wall after pre-combustion. These patches caused troubles with pumping out, and forced us to cut the tubes (and to connect them to the vacuum line) twice. Similar troubles occurred with one tube from experiment 8 in Table 3 (marked with "?" in Figure 3). Now we can avoid the patches (by rinsing the tubes extremely thoroughly) and confirmation of their influence on the background will require further ${ }^{14} \mathrm{C}$ measurements. Up to now, we must attribute the scatter of our background to the uncontrolled variations of combustion contamination, which determines the $1-\sigma$ interval of our background. The uncertainty of the background (Figure 1) is dependent on sample mass, and seems to be $\pm 0.13 \mathrm{pMC}$ and $\pm 0.09 \mathrm{pMC}$ for samples of $1 \mathrm{mg} \mathrm{C}$ and $1.5 \mathrm{mg} \mathrm{C}$, respectively. The corresponding error of dating (ca. $\pm 40 \mathrm{yr}$ for samples 10 ka old) allows us to use our line in routine ${ }^{14} \mathrm{C}$ dating.

Table 3 Parameters of combustion- and graphitization- mass dependence of ${ }^{14} \mathrm{C}$ concentration in the background samples, fitted to the data from two series of AMS measurements (Table 1). Three outlying points from first series (with $>1 \mathrm{pMC}$ for $\mathrm{m}_{\mathrm{c}}>1 \mathrm{mg}$, cf. the text) were rejected from calculations.

\begin{tabular}{lccc}
\hline & $k_{g}(\mathrm{mgC} \times \mathrm{pMC})$ & $k_{c}(\mathrm{mgC} \times \mathrm{pMC})$ & $A_{o}(\mathrm{pMC})$ \\
\hline First series & $-0.18 \pm 0.17$ & $0.58 \pm 0.14$ & $0.37 \pm 0.10$ \\
& $0^{\mathrm{a}}$ & $0.44 \pm 0.04^{\mathrm{a}}$ & $0.30 \pm 0.05^{\mathrm{a}}$ \\
Second series & $0.07 \pm 0.36$ & $0.15 \pm 0.44$ & $0.22 \pm 0.08$ \\
\hline
\end{tabular}

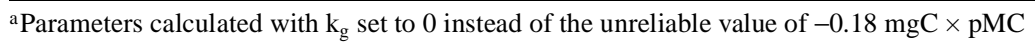

\section{CONCLUSION}

A comparison of two series of AMS ${ }^{14} \mathrm{C}$ measurements of background and standard (Ox-II) samples prepared in our laboratory indicated significant improvement in sample preparation purity. The main source of contamination introduced during the combustion appears to be the walls of the quartz tubes. That contamination has been lowered by pre-combustion of vacuum-sealed tubes, and currently the main source of contamination of background samples is graphitization. The reproducibility of background preparations is satisfactory, especially for samples larger than $1.5 \mathrm{mg} \mathrm{C}$ (better than $\pm 0.09 \mathrm{pMC}$ ). Despite still significant contamination with low- ${ }^{14} \mathrm{C}$ carbon during the graphitization process (corresponding to $1.2 \pm 0.2 \%$ of ${ }^{14} \mathrm{C}$-free carbon), good reproducibility of results allows us to use our line in routine ${ }^{14} \mathrm{C}$ dating.

\section{ACKNOWLEDGMENTS}

We thank P Grootes and the whole staff of the Leibniz-Labor, Kiel, Germany, for many remarks and advice during assembling and testing of our system, and for preparation of comparative $\mathrm{CO}_{2}$ samples. Thanks are also due to N Tisnerat-Laborde (LSCE, Gif-sur-Yvette, France) for sharing her 
experience in exploitation of the AMS combustion and graphitization systems. The critical comments of anonymous reviewer helped us greatly to improve the original version of the manuscript. This work has been sponsored by the Polish Committee for Scientific Research through the grant 6 P04E 04616 to TG.

\section{REFERENCES}

Goslar T, Czernik J. 2000. Sample preparation in the Gliwice Radiocarbon Laboratory for AMS ${ }^{14} \mathrm{C}$ dating of sediments. Geochronometria 18:1-8.

Kirner DL, Taylor RE, Southon JR. 1995. Reduction in backgrounds of microsamples for AMS ${ }^{14} \mathrm{C}$ dating. Radiocarbon 37(2): 697-704.

McNichol AP, Gagnon AR, Jones GA, Osborne EA. 1992. Illumination of a black box: analysis of gas composition during graphite target preparation. $\mathrm{Ra}$ diocarbon 34(3):321-9.

Nadeau M-J, Schleicher M, Grootes PM, Erlenkeuser H, Gottdang A, Mous DJW, Sarnthein JM, Willkomm H. 1997. The Leibniz-Labor AMS facility at the Christian-Albrechts University, Kiel, Germany. Nuclear Instruments and Methods in Physics Research B123:2230 .

Nadeau M-J, Grootes PM, Schleicher M, Hasselberg P, Rieck A, Bitterling M. 1998. Sample throughput and data quality at the Leibniz-Labor AMS facility. Radiocarbon 40(1):239-45.

Nadeau M-J, Grootes PM, Voelker AHL, Bruhn F, Duhr A, Oriwall, A. 2001. Carbonate ${ }^{14} \mathrm{C}$ background: does it have multiple personalities? Radiocarbon. This issue.
Pearson A, McNichol AP, Schneider RJ, von Reden KF, Zheng, Y. 1998. Microscale AMS ${ }^{14} \mathrm{C}$ measurements at NOSAMS. Radiocarbon 40(1):61-75.

Schleicher M, Grootes PM, Nadeau M-J, Schoon A. 1998. The carbonate ${ }^{14} \mathrm{C}$ background and its components at the Leibniz AMS facility. Radiocarbon 40(1): 85-93.

Sveinbjörnsdottir AE, Eiriksson J, Geirsdottir A, Heinemeier J, Rud N. 1993. The Fossvogur marine sediments in SW Iceland-confined to the AllerödYounger Dryas transition by AMS ${ }^{14} \mathrm{C}$ dating. Boreas 22:147-57.

Thomsen MS, Gulliksen S. 1992. Reduction of $\mathrm{CO}_{2}$-tographite conversion time of organic materials for ${ }^{14} \mathrm{C}$ AMS. Radiocarbon 34(3):330-4.

Vandeputte K, Moens L, Dams R, van der Plicht J. 1998. Study of the ${ }^{14} \mathrm{C}$-contamination potential of C-impurities in $\mathrm{CuO}$ and Fe. Radiocarbon 40(1):103-10.

Vogel JS, Nelson DE, Southon JR. 1987. ${ }^{14} \mathrm{C}$ background levels in an accelerator mass spectrometry system. $R a$ diocarbon 29(2B):323-33. 